\title{
Exploring the Social Status with Psychoactive and Physical Impacts of HIJRA Community: An Evidence Based Study on Khulna City, Bangladesh
}

\author{
Mohammad Asif Khan ${ }^{1}$ and Umme Habiba ${ }^{2} *$ \\ ${ }^{1 \& 2}$ Development Studies Discipline, Khulna University, Khulna, Bangladesh. \\ *Correspondence: habiba.ds@ku.ac.bd (Umme Habiba, Assistant Professor, Development Studies Discipline, Khulna \\ University, Bangladesh).
}

\begin{abstract}
The transgender people called HIJRA are one of the minor communities in Bangladesh. This research study was intended to explore the social status (education, religion, economy, civil-rights) and physical-psychoactive impacts of HIJRA community in Khulna, Bangladesh. We have already spent more than 48 years of liberation, but we haven't ensured the proper human rights for HIJRAs. The following study aims to find out some major issues (like social status and psychological behavior) from HIJRAs. To acquire those results it uses the questionnaire survey. The study exposed that they are one of the underprivileged and unlearned communities in Bangladesh. Though they have their own gender recognition, they are subjected to a terrifying tribulation in their daily life. In the development policy, this discrimination hinders the goals of inner and outer development. For fetching the outcome of this study, researchers used both exploratory and descriptive analysis method with qualitative and quantitative research approach. Furthermore, the findings of this study are - (a) Economic condition of the HIJRAs. (b) Religious and educational information of the HIJRAs, and (c) Physical and psychoactive issues which caused some dangerous issues on their life.
\end{abstract}

Keywords: HIJRA, Religion, Economy, Psychoactive, Psychology, Gender, Human rights, and Bangladesh.

\section{INTRODUCTION:}

HIJRA is one of the poorest and loneliest communities in the south-eastern part of Asia especially Bangladesh. Almighty creates human, different from one another, which are living together in the universe. Generally we can see two types of peoples in our ambience. We can define them as male and female but there are also some people who had not the same or all the characteristics of male and female genders is identified as Hermaphrodite/eunuch people (commonly called HIJRA in Indian sub-continent). Jebin, (2019) said that the society and the true sexual identity UniversePG I www.universepg.com of every individual are the main life-cycle of the HIJRAs. Third-gender or Transgender referred HIJRA in the South-Asia, environ in the group of genderobeying people, including transvestites, transsexuals, intersex, individuals, and transgender people (Aziz and Azhar, 2019). Khateeb and Shaheen, (2015) expressed that the number which has a well-known roles within Indian sub continental cultures of HIJRAs, part gender-luminal, part spiritual and part survival history. Popay et al. (2008) stated that the imbalanced power relationships of HIJRAs are mainly depends on social exclusion which results across the 
dimensions of culture, economics, politics and interpersonal relationships. As of late HIJRAs have got the sex identity from Bangladesh government, so everyone started to permit them in every movement of formal and official documents in between nation (Stenqvist, 2015). Although they have a long existed history of their own culture in Bangladesh and in no time they got their HIJRA (sex) identity which was legally recognized as third gender in Bangladesh (Hossain, 2017).

The key objectives of this study are to point out the social status and the problems that they (HIJRAtransgender) were faced frequently in Bangladesh. This study has set the following specific objectives: To explore the socio-economic condition of HIJRA community; to determine the physical and psychological impact of HIJRA. The relevance of this study was to furnish meeting point on this overlooked and unlearned community. According to Sinha, (2016) Transgender people resided in hidden corners of our society, they can't able to consign their community within main stream societal tier (Sema, 2019; Sema and Islam, 2020). Furthermore, people deprived HIJRAs by diminishing their rights.

After the liberation war of Bangladesh, first population consensus of Khulna district held in the year 1974 expressed that there were 134 HIJRAs in urban, 106 HIJRAs in rural and the 114 HIJRAs were living in city area and In the year 2011,108 HIJRAs were living in urban area, 101 HIJRAs were living in rural area and 103 HIJRAs were living in city area (BBS, 2011). The statistics showed that over the years, number of HIJRA population was decreased in both of the areas. There has a lacking of basic rights among HIJRAs with equality and education, so they are still living on the shadow of rejection in society (Islam, 2016).

Hence the present study was sought to discuss about their lifestyle, social life cycle, physical and psychological comfort range etc. HIJRAs face social barriers as they have physical and psychological ambivalence, these situation fetch them freaks (hiding their sexual identity) (Jami, 2005). This paper justified social status of HIJRA community and their psychological problems for live life.

UniversePG I www.universepg.com

\section{MATERIALS AND METHODS:}

This study was conducted with exploratory and descriptive analysis design with homogenous purposive sampling where both qualitative and quantitative approaches were combined to collect data. Primary and Secondary dataset was used for amassing information. Interview schedule technique was used to take face-to-face interview for acquiring data from respondents.

Primary data was used for interview technique. The Base survey of this study was conducted by using the formula of Yamane (1967:886) where total population was 500, and level of precision was .08. Following the formula total respondents of this study was 119 . This study employed a homogenous purposive sampling for preparing interview schedule to take face-to-face interview with close ended-question papers. The faceto-face interview of this study was conducted on the last week of November 2019, each of the interviews took approximately 15-20 minutes and finally it took 2 days to accomplish the whole survey.

The survey of this study was examined in Khulna city, which is located on the southern part of Bangladesh. HIJRAs, from study area, were interviewed with the intention of knowing their life styles, woes, incomes, physical and psycho-active conditions. Exploring HIJRAs status and their physical-psychoactive condition was main area under discussion. Researchers took some ethics for exploring the study which referred confidentiality, legality and beneficence (do not harm).

\section{RESULTS AND DISCUSSIONS:}

\subsection{Residence}

Every HIJRA community (locally called Para) has its own head, which sets the rules and regulations for their members. The head, known as Guru MA (mother), was the pedestal head of their community. In the absence of Guru Ma, there was another head under her. She was known as the right hand of head. In this study area, Guru Ma's name was Panna Ma and the name of her right hand was Mou ma. Gura Ma played a great role to fetch HIJRAs in their existing community. She and her people stalked in between city and search of HIJRAs. When they got to know the 
information of newborn HIJRA baby, they talked with their parents and manage them to fetch their child to this community after growing up. Except Guru MA, some relatives of newborn HIJRAs was responsible for ejecting them here for not bearing the social ignorance from their neighborhood. Despite of being adapted themselves in community some of them had an acute desire to go back to their family but most of them were not. Though the HIJRA marriage was the outlawed concept in context of Bangladeshi culture there were three HIJRAs in this community who got married by introducing themselves as a woman (most of them were felt comfortable to introduce themselves as women).

\section{Marital Status}

In India bisexual marriages has got legitimated but in our country it hasn't recognized yet said by respondents. There has no legitimacy to get married in Bangladesh. Only 2.5\% among them was getting married in study area though there had some complexities to HIJRA marriage.

Table 1: Marital Status of Respondents

\begin{tabular}{|l|c|c|}
\hline Marital Status & Frequency & Percentage \\
\hline Married & 3 & $2.5 \%$ \\
\hline Unmarried & 116 & $97.5 \%$ \\
\hline \multicolumn{1}{|c|}{ Total } & $\mathbf{1 1 9}$ & $\mathbf{1 0 0 . 0 \%}$ \\
\hline
\end{tabular}

\section{Causes of Leaving Home}

They leaved home for the reason of having HIJRA identity whereas people weren't considering them as human so they felt hurt and leave their houses.

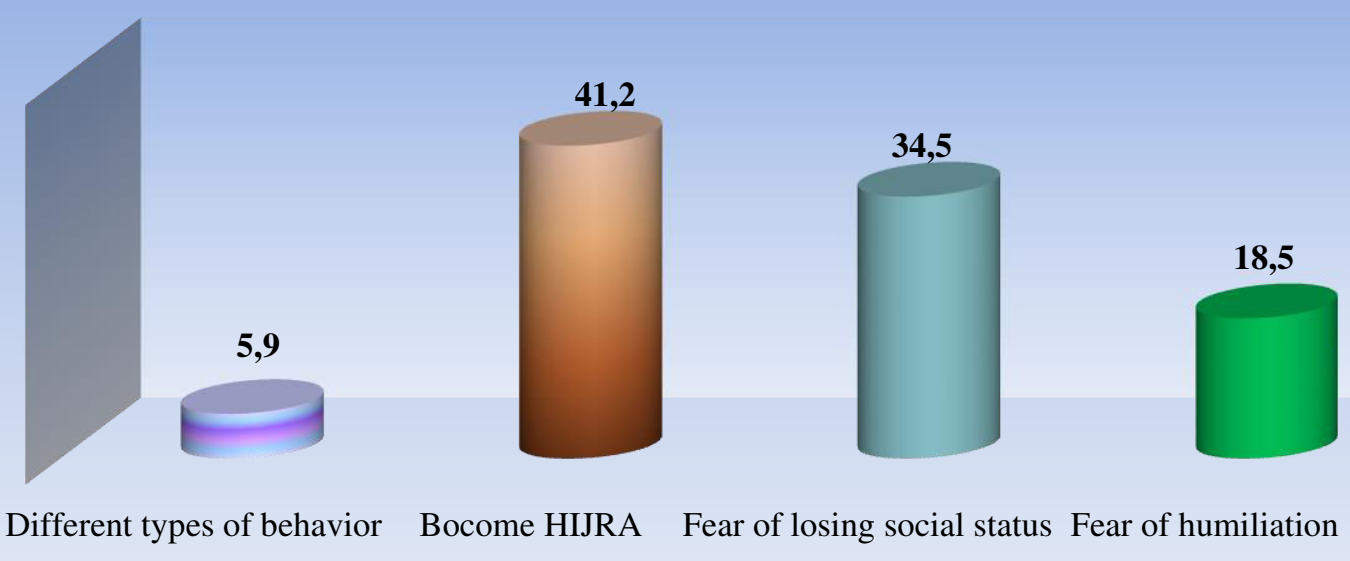

Fig 1: Causes of leaving home.

\subsection{Religious and Educational Factors}

According to the Information of study area HIJRAs weren't attending any social and family oriented programs, because they had not got the permission to attend those programs. As consequences, Majority of them hadn't able to take institutional education from school because of getting hatred by others. In school, almost every student gave bad expressions to them. Muslims and Hindus were the most practiced religion here. 92\% HIJRAs were Muslims, and rests were Hindus. It was quite impossible to know about HIJRA lifestyle and their religion. But this study got that, maximum HIJRAs in community believe on their religion, whereas almost $91 \%$ had a strong believe in religion. Implausible consequence of this research was they learn and strongly follow the religious rules; a UniversePG I www.universepg.com religious father (called IMAM) came to their community to teach religious lessons. Most unseen and unknown outcome from the study was the funeral process of them. Facts of this process are that when any HIJRA died in their community, the community members arranged funeral process according to their religious statement. Muslim corpses were buried in the grave and the Hindus corpses were burnt in the crematorium.

\section{Study}

There were 93\% HIJRA leaved their school after completing Primary level and the very few of $7 \%$ HIJRA passed their Secondary level. So as a minor group of our society almost every one of them hadn't has academic qualification and it was very substandard matter for our society. 


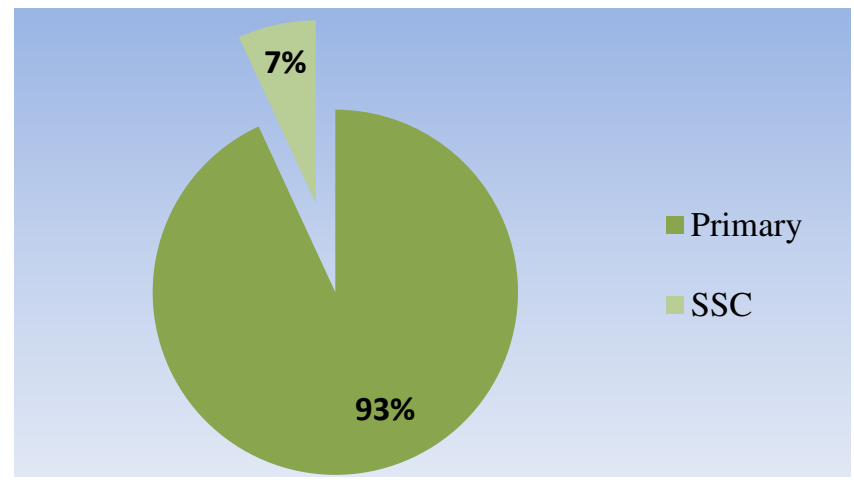

Fig 2: Study details.

\section{Reasons of not going school}

There were a majority of $60.4 \%$ HIJRAs who got hatred from others. In school, almost every student gave bad expressions to them. So they had got bad feelings and lost courage to go to schools, then $39.6 \%$ HIJRA as who said they have got abused for being HIJRA by their fellow mate.

Table 2: Reasons of not going school

\begin{tabular}{|l|c|c|}
\hline \multicolumn{1}{|c|}{ Reasons } & Frequency & Percentage \\
\hline For hatred & 32 & $60.4 \%$ \\
\hline For being a HIJRA & 21 & $39.6 \%$ \\
\hline \multicolumn{1}{|c|}{ Total } & $\mathbf{5 3}$ & $\mathbf{1 0 0 . 0 \%}$ \\
\hline
\end{tabular}

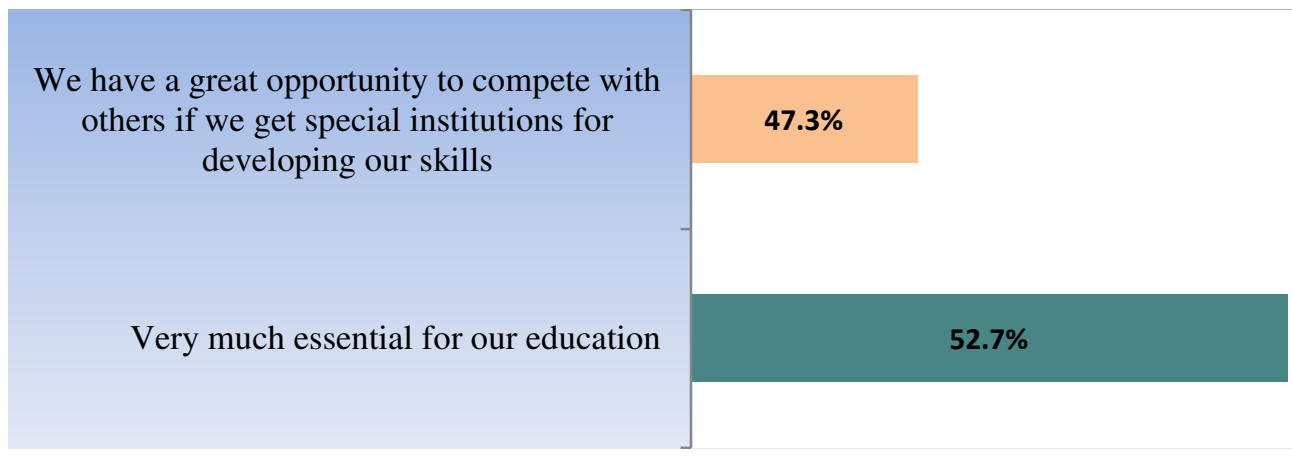

Fig 3: Necessity of Specialized Institutions.

Table 3: Funeral Process

\begin{tabular}{c|c|c}
\hline Funeral Process & Frequency & Percentage \\
\hline Bury in Grave & 109 & $91.6 \%$ \\
\hline Burn the corpse & 10 & $8.4 \%$ \\
\hline Total & $\mathbf{1 1 9}$ & $\mathbf{1 0 0 . 0 \%}$ \\
\hline
\end{tabular}

\subsection{Civil Rights}

\section{Necessity of Specialized Institutions for HIJRA Education}

Countries like Bangladesh, there are so many minor groups. Many of them aren't getting the fundamental rights from society. Education is the thing by which a country can provide a skilled people to world who will participate to the development of country's welfare but minors like - HIJRAs can't engage them to participate in every sector of country. So they need specialized institutions to develop themselves. Study found that there were $52.7 \%$ people who thought about specialized institution needs for better education, other $47.3 \%$ people thought if they had got specialized institutions then they had a great opportunity for competing with others and develop their skills.

\section{Religion}

Most of HIJRAs were Muslims in the study area. They got it by born but there had some people who came as non-Muslims, after coming here they changed their religion and convert into Muslims and $8 \%$ HIJRA were Hindus. There hadn't other religious people except those two.

National Identity Card (NID) is called the citizenship identity in Bangladesh. According to the study before HIJRA recognition, some got NID by introducing themselves as female but maximum HIJRAs hadn't got their NID before recognition of their own gender said by the respondent. Majority of $89 \%$ HIJRAs said that they got the NID after the declaration of HIJRA as third gender. Despite of being getting HIJRA recog- 
nition, they hadn't able for availing the opportunity of getting government job, medical opportunities from hospitals and other national facilities yet.

\section{National Identity Card (NID)}

There were 93.3\% HIJRA who had NID, in the study area and other $6.7 \%$ people hadn't NID (of whom majority hadn't met the minimum age of enlisting NID process). $89 \%$ HIJRAs said they got NID after the declaration of HIJRA as third gender, then $11 \%$ HIJRAs said they got NID before the declaration of HIJRA as third-gender. There are $85.7 \%$ HIJRAs said they had got opportunity to enter into any government job, and other $14.3 \%$ HIJRAs said they hadn't enough opportunity to enter into any government job.

\section{Contamination of STI (Sexually Transmitted Infec- tions), sexual disease including HIV/AIDS}

Study found that there were $78.2 \%$ HIJRAs thought that there had so much probability for getting contaminated with STI and sexual diseases and other 21.8\% HIJRAs were saying that there had no possibility for getting contaminated with STI, and sexual diseases. Contrasts to diseases they had also got the opportunities of getting treatment on clinic and govt. hospitals and clinic. $68.9 \%$ HIJRAs said they had got the access to govt. hospitals or clinic for treatment, and other $31.1 \%$ HIJRA were saying there hadn't access to govt. hospitals or clinic for treatment.

\subsection{Economic Factors}

No one comes to hire HIJRAs for job; they chose some ways to maintain their livelihood. Those are collecting money from shops, Baby dancing and own business for their livelihood. Almost $61 \%$ of them were related with collecting money from shops, $32 \%$ were related with baby dancing and others had their own business. They had also other ways to collect money for instance selling liquor which hadn't got legitimacy in Bangladesh, random sexual activities, etc. Average monthly income of HIJRAs was BDT 12,815 whereas the monthly average expenditure was BDT 8,504 which is quite low on Bangladeshi perspectives. There were no other working possibilities for them in societal context of Bangladesh, as 92.4\% HIJRA hadn't any working opportunity in home or hotel. So the scenario was very much squeezes for them.

\section{Main Profession}

There are $60.5 \%$ HIJRAs said collecting money from shops were their main profession to lead their livelihood, and other $31.9 \%$ HIJRAs said they led their life by dancing babies from houses, and rest of 7.6\% HIJRA had their own business.

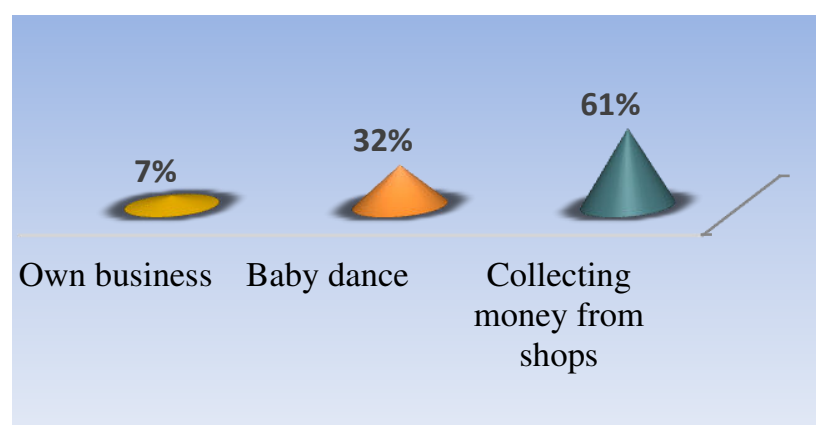

Fig 4: Main Profession.

\section{Income and Expenditure}

Though they earned money by doing such things, but after getting money they gave total money to their respective Ma. Their Ma gave money to them when they required it. So that income wasn't their property at all.

\subsection{Physical and Psychological Factors}

In its shortest form, psychosocial factors had influenced by social environment. For anyone, physical and psychological stamina had an important factor of daily life. It expressed strength of human being. Because when person faced vulnerable situation in life, if he or she hadn't enough physical and mental stability so he/she got tear down in life. As a minor group they lived in their own association. They couldn't do anything like others. So there was a high probability of getting affected by mental and physical disorder by environment (Table 5).

Table 4: Income and Expenditure Information of Respondents

\begin{tabular}{c|c|c}
\hline Income/Expenditure Range & Income Percentage & Expenditure Percentage \\
\hline $0-7,999$ BDT & $24 \%$ & $76 \%$ \\
\hline $8,000-9,999$ BDT & $25 \%$ & $17 \%$ \\
\hline
\end{tabular}




\begin{tabular}{r|r|r}
\hline $10,000-11,999$ BDT & $24 \%$ & $4 \%$ \\
\hline $12,000-14,999$ BDT & $18 \%$ & $2 \%$ \\
\hline $15,000-$ above BDT & $9 \%$ & $1 \%$ \\
\hline
\end{tabular}

Table 5: Physical and Psychological Information of Respondents

\begin{tabular}{c|c|c|c|c|c|c|c|c}
\hline \multirow{2}{*}{ Answer } & \multicolumn{2}{|c|}{$\begin{array}{c}\text { Psychoactive } \\
\text { discomfort }\end{array}$} & \multicolumn{2}{c|}{ Loneliness } & \multicolumn{2}{c|}{ Suicidal Attempts } & \multicolumn{2}{c}{ Physical Uneasiness } \\
\cline { 2 - 9 } & Frequency & Percentage & $\begin{array}{c}\text { Frequen } \\
\text { cy }\end{array}$ & Percentage & Frequency & Percentage & Frequency & Percentage \\
\hline Yes & 83 & $69.7 \%$ & 48 & $40.3 \%$ & 102 & $85.7 \%$ & 104 & $47.4 \%$ \\
\cline { 2 - 9 } No & 36 & $30 . \%$ & 32 & $26.9 \%$ & 17 & $14.3 \%$ & 15 & $12.6 \%$ \\
\cline { 2 - 9 } $\begin{array}{c}\text { Most } \\
\text { often }\end{array}$ & - & - & 39 & $32.8 \%$ & - & - & - & - \\
TOTAL & $\mathbf{1 1 9}$ & $\mathbf{1 0 0 . 0 \%}$ & $\mathbf{1 1 9}$ & $\mathbf{1 0 0 . 0 \%}$ & $\mathbf{1 1 9}$ & $\mathbf{1 0 0 . 0 \%}$ & $\mathbf{1 1 9}$ & $\mathbf{1 0 0 . 0 \%}$ \\
\hline
\end{tabular}

\section{Reasons for being suffered from physical uneasiness}

There were $28.6 \%$ HIJRAs said they felt uneasiness for their sex, other $24.4 \%$ HIJRAs said they felt uneasiness for living parochial area, 21\% HIJRA felt uneasiness for leading grimy livelihood, $13.4 \%$ HIJRAs said they felt uneasiness for social exclusion, the rest $12.6 \%$ HIJRAs said none because they hadn't felt any physical uneasiness

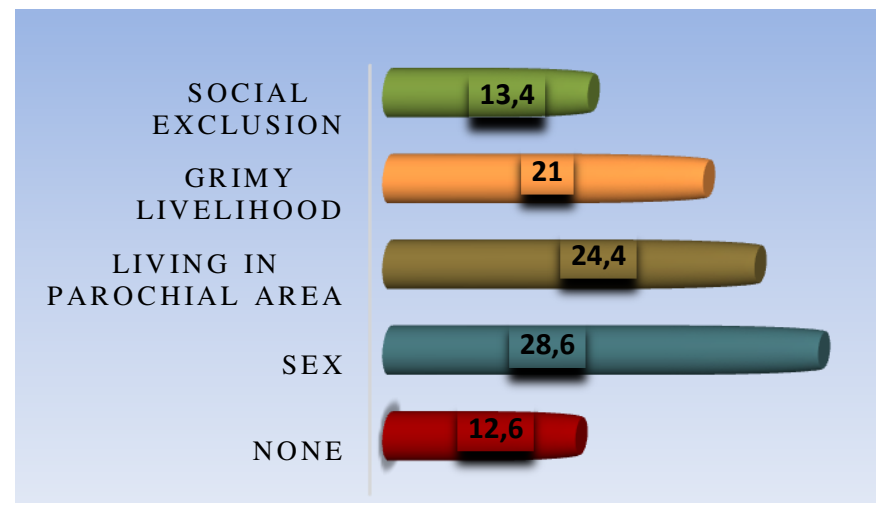

Fig 5: Reasons of Physical Uneasiness.

Shown figure told us HIJRAs got physical uneasiness for sexual misconduct which had the main concern of this paper. It shouldn't be happened with them because they hadn't been responsible for their sexual oddness.

\section{Reasons of attempting suicide}

Figure showed that the people who were attempt to suicide because of missing their family, remaining reasons were loneliness, mental stress and abusive behaviors.

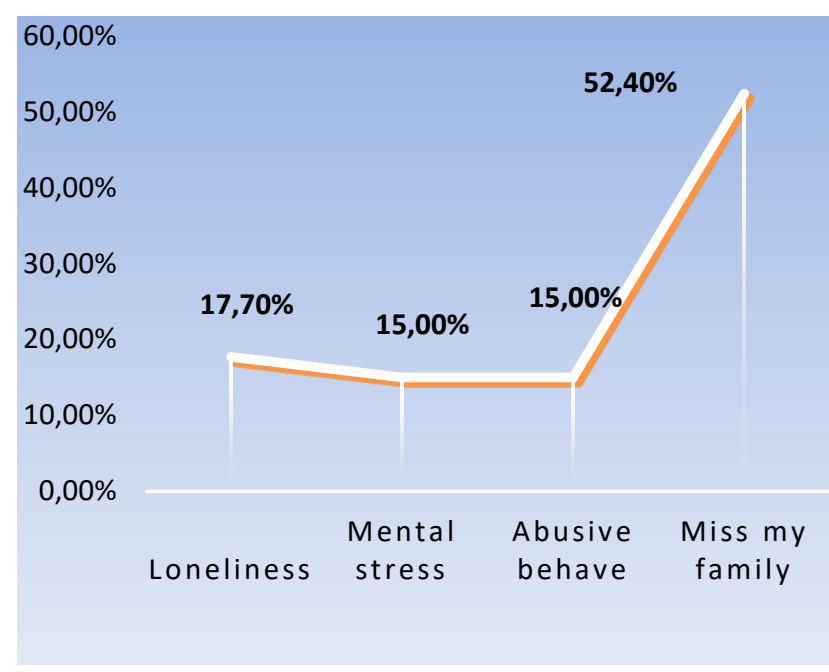

Fig 6: Reasons of Attempting Suicide.

Reasons were classified into 4 ways, those are Loneliness, mental stress, abusive behavior and missing families. Most of them attempted suicide because missing of their families.

\section{Harassments}

Table 6 revealed the HIJRA harassments which occur over the various societal levels. Most of HIJRAs were affected by beating.

Since the $\mathrm{P}$ value is less than chosen significance level $=0.05$, null hypothesis is rejected. So the alternative hypothesis is accepted and can be concluded that, there is relationship between loneliness and suicidal attempts (Table 7). 
Table 6: Harassments

\begin{tabular}{|c|c|c|}
\hline Harassments & Frequency & Percentage \\
\hline Beating & 24 & $20.2 \%$ \\
\hline Physical Abuse & 20 & $16.8 \%$ \\
\hline Shoeing away & 19 & $16.0 \%$ \\
\hline Push the neck from offices & 19 & $16.0 \%$ \\
\hline Sex without consent & 19 & $16.0 \%$ \\
\hline Restricting interaction with others & 18 & $15.1 \%$ \\
\hline Total & 119 & $100.0 \%$ \\
\hline
\end{tabular}

\subsection{Hypothesis Testing}

\subsubsection{Chi-Square Tests - 1}

Null hypothesis $\left(\mathbf{H}_{\mathbf{0}}\right)$ : There is no association between loneliness and suicidal attempts

Alternative hypothesis $\left(\mathbf{H}_{\mathbf{1}}\right)$ : There is association between loneliness and suicidal attempts

Table 7: Chi-square test 1

\begin{tabular}{lccc}
\hline & Value & df & Asymp. Sig. (2-sided) \\
\hline Pearson Chi-Square & $8.240^{\mathrm{a}}$ & 2 & .016 \\
Likelihood Ratio & 9.296 & 2 & .010 \\
Linear-by-Linear Association & 5.905 & 1 & .015 \\
N of Valid Cases & 119 & & \\
\hline
\end{tabular}

\subsubsection{Chi-Square Tests - 2}

Null hypothesis $\left(\mathbf{H}_{\mathbf{0}}\right)$ : There is no association between income adequacy and selling liquor Alternative hypothesis $\left(\mathbf{H}_{\mathbf{1}}\right)$ : There is association between income adequacy and selling liquor

Table 8: Chi-square test 2

\begin{tabular}{lccc}
\hline & Value & df & Asymp. Sig. (2-sided) \\
\hline Pearson Chi-Square & $4.610^{\mathrm{a}}$ & 1 & .032 \\
Likelihood Ratio & 4.695 & 1 & .030 \\
Linear-by-Linear Association & 4.571 & 1 & .033 \\
N of Valid Cases & 119 & & \\
\hline
\end{tabular}

Since the $\mathrm{P}$ value is less than chosen significance level $=0.05$, null hypothesis is rejected. So the alternative hypothesis is accepted and it can be concluded that, there is relationship between income adequacy and selling liquor.

\subsection{Case Study}

\subsubsection{Case Study 1}

Mohua HIJRA (pseudonym) was 34 years old. Mohua felt comfort to give introduce herself as female. She had been living here for 30 years. At age of four, her father came here to note the formalities of letting her in this community. From then she was living here in

UniversePG I www.universepg.com
Bormashil. Her hometown was in Phultala, Khulna. She hadn't any connection to her family now. Her family member closed the door for her. She hadn't have any academic education in life, but after came to this community she took some basic education from home tutors. Their Guru-MA managed teachers to give basic education for HIJRA who hadn't have literacy. She felt alone when she thought she had a family like others but couldn't able to make any connections with them. In this community, she actually led her life by collecting money from shops with others. She said she hadn't liked these manners because for these works people didn't like us and they felt afraid of seeing us so they hate us though we hadn't other ways to show 
the way to live. If government will give us some opportunities to engage with other jobs then it will easy for us to leave these types of misdeeds.

Income of doing these works wasn't enough to lead our lives because we have to give all money to our guru ma then she kept them all and the place we lived was not suited to live on. She had some disease and she had to spend partial amount of money to buy medicines. She said peoples of these communities are affected by some diseases, so they have to buy medicines but they hadn't their own savings. She wanted to seek the vision of government to overlap their fortunes. At the end she said 'I am happy with what Allah has fixed for me".

\subsubsection{Case Study 2}

Rupa HIJRA (pseudonym) was 29 years old. Rupa left home at the age of 10 years. She left home while she was a student of class Six. She completed her primary level, but couldn't continue her study. As she grew up, her behave and physical inconsistency began to notice and started to get mockery by others. She didn't take those mockeries with fine manner and leave her home for good. After leaving home, she spent some days in Railway station. In railway station, she met a person and found the person like her. Mainly she brought her in this community.

After coming here, she knew the person who fetched her here is called Guru-Ma of this community. From then Guru-ma loved her most. Rupa now involved with local politics as well. She said politics is one of the finest ways to change our situations. She also participated on HIJRA recognition movement. She has the connection with her family. She went her house most often and met with parents. After leaving home, her family members tried hard to return her in house. She finally asked prayers for herself so that she can able to change their community members' fortune.

\section{CONCLUSION:}

This study was intended to assess the socio economic status of the HIJRA community. Using various statistical and analytical tools this study revealed that HIJRA people are less educated, their economic condition is very low compared to others, they have got less civil rights than others, they are physically and psychologically weak than others too. In other words they are the most vulnerable groups in Bangladesh. People hate them with abusive behaviors. They hadn't any established social status on the society. HIJRAs will be highly benefited if government pays more concern for making the services available, accessible and promote the quality of services for individuals and community.

\section{ACKNOWLEDGEMENT:}

At first we would like to thanks the almighty Allah for giving us the opportunity to accomplish this study. Our parents gave us the courage to bring the immaterialist idea into this materialistic paper. Last but not the least we would like to thank all of our well-wishers with friends, colleagues, juniors and seniors.

\section{CONFLICTS OF INTEREST:}

We declared that this paper has no conflict of interest with other authors in the terms of ownership or authorship of this paper.

\section{REFERENCES:}

1) Aziz, A., and Azhar, S. (2019). Social Exclusion and Official Recognition for Hijra in Bangladesh. Journal of Research on Women and Gender, 9, 3-19.

https://digital.library.txstate.edu/handle/10877/1 $\underline{2901}$

2) Bangladesh Bureau of Statistics (BBS), Statistics and Informatics Division (SID), Ministry of Planning, Government of the Peoples Republic of Bangladesh, (2015). Bangladesh population and housing census 2011: Zila report: Khulna. Dhaka.

3) Hossain, A. (2017). The paradox of recognition: hijra, third gender and sexual rights in Bangladesh. Culture, Health \& Sexuality, 19(12), pp. 1418-1431. https://doi.org/10.1080/13691058.2017.1317831

4) Islam, A. (2016). Right to Education of The Third Gender of Bangladesh: An overview. IOSR Journal of Humanities and Social Science, 21(9), pp. 29-34. http://www.iosrjournals.org/iosr-jhss/papers/Vo 1.\%2021\%20Issue9/Version-7/E2109072934.pdf 
5) Jami, H. (2005). July. Condition and status of hijras (transgender, transvestites etc.) in Pakistan. In Sexualities, Genders and Rights in Asia', $1^{\text {st }}$ International Conference of Asian Queer Studies Retrieved September, 5, p. 2006.

6) Jebin, L. (2019). Status of Transgender People in Bangladesh: A Socio-economic-analysis. South Asian Journal of Policy and Governance, 42(1), pp. 49-63.

http://sjpgjournal.org/index.php/sjpg/article/view $\underline{122}$

7) Khateeb, S. and Shaheen, A. (2015). An Analytical Study of the Socio-Economic Problems of Third Gender. Journal of Social Economics, 2(2), pp. 84-88.

https://ideas.repec.org/a/rss/jnljse/v2i2p4.html

8) Popay, J., Escorel, S., Hernández, N., Johnston, H., Mathieson, J., Rispel L. (2008). Lancaster: Social Exclusion Knowledge Network; Understanding and tracking social exclusion: final report to the WHO Commission on Social Determinants of Health; pp. 207.

9) Sema SA. (2019). The subversive use of parading effeminacy by transgender people in increasing crime rate in Bangladesh: a study on several investigating crime reports, $\mathrm{Br} . J$. Arts Humanit., 1(6), 45-55.

https://doi.org/10.34104/bjah.019.045055

10) Sema SA., and Islam MT. (2020). Empowerment state of transgender people in Bangladesh: a study on Savar national memorial based area in Dhaka city, Asian J. Soc. Sci. Leg. Stud., 2(1), 1-10.

https://doi.org/10.34104/ajssls.020.01010

11) Sinha, S. (2016). Social Exclusion of Transgender in the Civil Society: A Case Study of the Status of the Transgender in Kolkata. International Journal of Sociology, Social Anthropology and Social Policy, 2(1), pp. 5873.

http://oaji.net/articles/2016/1115-147677836 3.pdf

12) Stenqvist, T. (2015). The social struggle of being HIJRA in Bangladesh-cultural aspiration between inclusion and illegitimacy. $I^{\text {st }}$ year master student thesis. Pp. 1-55. https://muep.mau.se/handle/2043/18568

Citation: Khan MA., and Habiba U. (2021). Exploring the social status with psychoactive and physical impacts of the HIJRA community: an evidence based study on Khulna city, Bangladesh, Asian J. Soc. Sci. Leg. Stud., 3(1), 1-9. https://doi.org/10.34104/ajssls.021.0109 @) @ 